\title{
Aneurysm of a right-sided aortic arch and right descending aorta: Three-dimensional volume rendering of multislice computed tomographic aortography facilitates surgical planning and management
}

Peter J. Oberwalder, MD, ${ }^{a}$ Peter Bergmann, MD, ${ }^{a}$ Manfred Tillich, MD, ${ }^{\mathrm{b}}$ and Bruno Rigler, MD, Graz, Austria

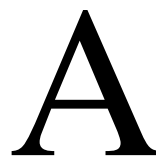

ortic aneurysms of the right-sided aortic arch and a subsequent descending aorta with an aberrant left subclavian artery (ALSA) are rather uncommon ( $0.05 \%$ of the population), with only a few cases reported. ${ }^{1-4}$ We describe a successful surgical repair of this vascular congenital anomaly after a previous accurate imaging technique, demonstrating the atypical arrangement of the brachiocephalic arteries of this malformation.

\section{Clinical Summary}

A 55-year-old man who was otherwise asymptomatic was planned for elective excision of multiple lipomas on his thorax wall.

Preoperative evaluation showed a huge aneurysm $(8 \mathrm{~cm})$ of the descending aorta on chest radiography. Further investigation was carried out.

Multislice computed tomographic aortography (MSCTA) revealed a right-sided descending aortic aneurysm originating at the distal right-sided aortic arch. Furthermore, an ALSA without dilatation was present, arising from the upper third of the descending aorta.

Volume rendering of MSCTA created 3-dimensional images of the aortic pathology, which allowed a more accurate evaluation of the brachiocephalic arteries (Figure 1), thereby facilitating planning of the surgical strategy. Arrangement of the brachiocephalic arteries consisted of the following: A left common carotid artery arose as the first branch from the ascending aorta, followed by the right common carotid artery and a right subclavian artery. The left subclavian artery originated from the left lateral aspect of the anterior wall of the right-sided descending aorta at the level of TH 3 and passed to the left behind the trachea and esophagus (Figure 2).

\section{Surgical Technique}

Cardiopulmonary bypass was established through a right anterolateral thoracotomy in the fourth intercostal space, with cannula-

\footnotetext{
From the Departments of Cardiac Surgery and Radiology, ${ }^{\mathrm{b}}$ Medical School Graz, Graz, Austria.

Received for publication July 19, 2004; revisions received Aug 6, 2004; accepted for publication Aug 18, 2004.

Address for reprints: Peter J Oberwalder, MD, Department of Cardiac Surgery, Medical School Graz, Auenbruggerplatz 29, 8036 Graz, Austria (E-mail: peter.oberwalder@meduni-graz.at).

J Thorac Cardiovasc Surg 2005;129:953-4

$0022-5223 / \$ 30.00$

Copyright $\odot 2005$ by The American Association for Thoracic Surgery doi:10.1016/j.jtcvs.2004.08.035
}

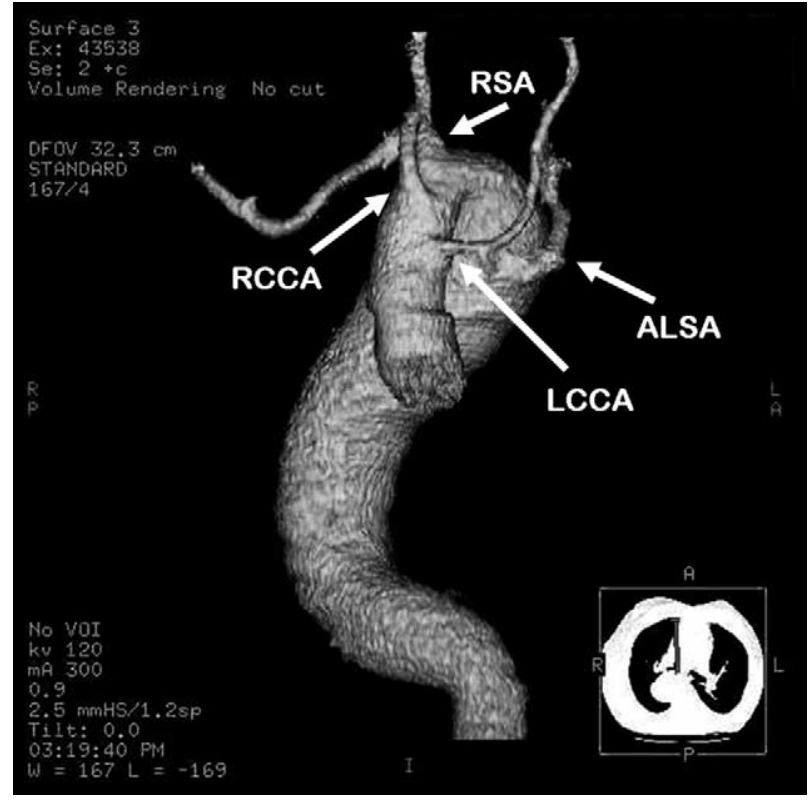

Figure 1. Three-dimensional image of the aneurysm and brachiocephalic arteries. ALSA, Aberrant left subclavian artery; LCCA, left common carotid artery; RCCA, right common carotid artery; $R S A$, right subclavian artery.

tion of the ascending aorta and the right atrium. After cooling to a core temperature of $28^{\circ} \mathrm{C}$, the aorta was clamped behind the origin of the right subclavian artery at the distal aortic arch. An additional clamp was placed at the mid descending aorta, and a $21 \mathrm{~F}$ cannula was inserted and connected through a $\mathrm{Y}$ to the arterial perfusion line for distal aortic perfusion. The aneurysm was opened and resected, and the distal aortic arch and the entire descending aorta were then replaced with a 24-mm double-velour woven Hemashield graft (Boston Scientific, Natick, Mass). The orifice of the ALSA was anastomosed to an 8-mm Hemashield graft. The proximal end of this graft was then anastomosed to the aortic graft in an end-to-side fashion (Figure 3). In addition, all intercostal arteries from the level of TH 9 down to TH 11 were reimplanted as patches into the distal aortic graft. The patient was awake and extubated 3 hours postoperatively without any neurologic symptoms.

The further postoperative course was uneventful, and the patient was discharged at postoperative day 8 .

\section{Discussion}

The right aortic arch with ALSA alone as an isolated anomaly is extremely rare. It results from regression of the left fourth aortic 


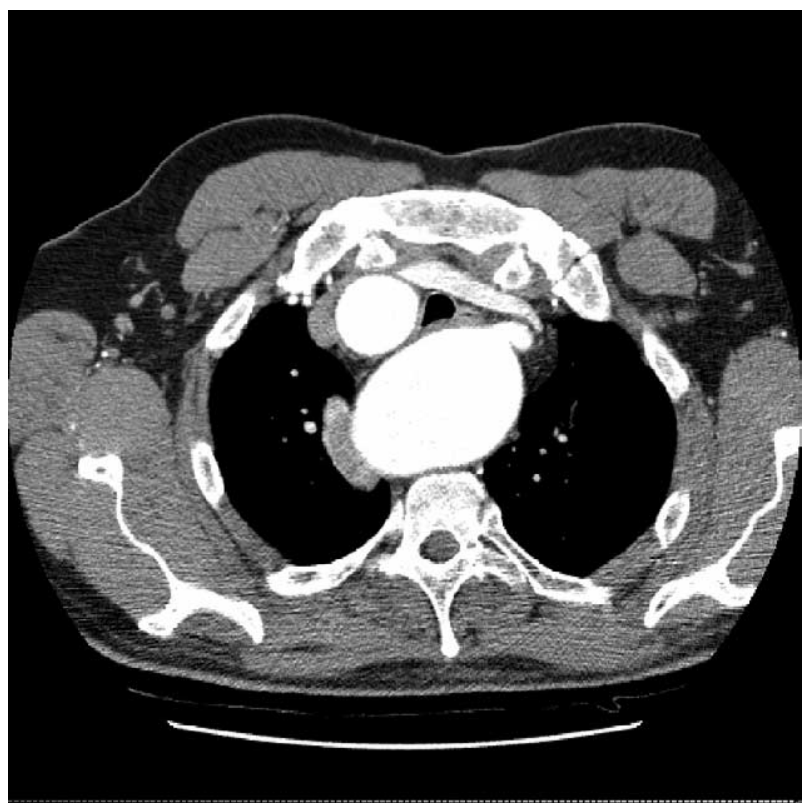

Figure 2. Origin of the aberrant left subclavian artery.

arch between the left common carotid and left subclavian arteries. When associated with an ALSA, there is a 5\% to $10 \%$ incidence of accompanying congenital heart disease, including tetralogy of Fallot, atrial septal defect, ventricular septal defect, and coarctation of the aorta. This anomaly is often an incidental finding. About 5\% will experience compression symptoms from the vascular ring completed by the ductus or ligamentum arteriosum. In these patients a large aortic (Kommerell) diverticulum is often present. This diverticulum connects the left subclavian artery and the left-sided ligamentum arteriosum.

Our patient had an aneurysm of the distal right-sided aortic arch and the entire descending aorta with a normal wide left subclavian artery, and there were no findings of an enlarged Kommerel diverticulum. The patient was free of any symptoms, and no compression of the esophagus or trachea could be found, possibly because of a missing vascular ring and an aneurysmatic Kommerel diverticulum. The left subclavian artery originated rather low from the right descending aorta (level TH 3).

An accurate preoperative evaluation of the congenital vascular malformation is mandatory for successful surgical repair. MSCTA, with its rapid data acquisition and high spatial resolution, is an excellent means for the evaluation of anomalies of the thoracic aorta because it enables visualization of the aortic lesion's size, location, and extent. Volume rendering creates 3-dimensional images of the aorta, which improve diagnostic accuracy and facilitate surgical planning.

The methods of treatment often include the use of deep hypothermic circulatory arrest to repair the sometimes complex lesions of the distal arch. For repair of the distal aortic arch and the descending aorta, a tubular graft is used. The ALSA is reattached to the tubular graft by using an interposition graft.

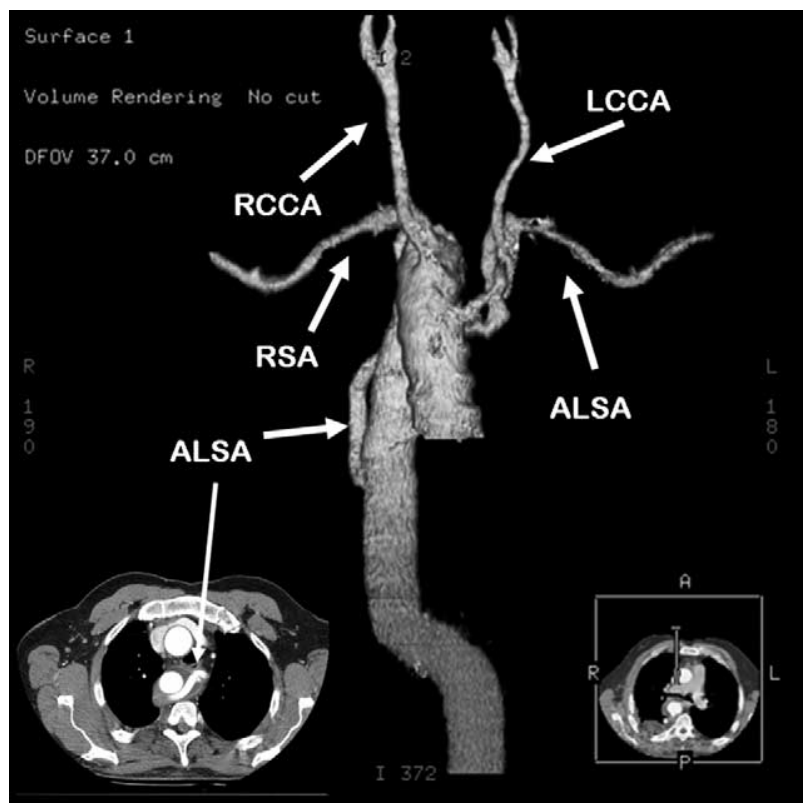

Figure 3. Postoperative 3-D image of the aortic reconstruction. $A L S A$, Aberrant left subclavian artery; $L C C A$, left common carotid artery; $R C C A$, right common carotid artery; $R S A$, right subclavian artery. Inset, Axial CT image: course of the ALSA originating on the dorsal descending aorta.

As with every surgical procedure on the aortic arch, adequate brain protection is essential for preventing neurologic damage. Deep hypothermic circulatory arrest with or without antegrade cerebral perfusion might be very useful. In our patient circulatory arrest could be avoided because of the anatomy of the head vessels. Cerebral perfusion was maintained by means of regular cardiopulmonary bypass through the aortic cannula. Spinal cord protection was achieved by using moderate hypothermia and perfusion of the distal descending aorta through an additional arterial cannula. In addition, reimplantation of critical intercostal arteries was performed.

\section{References}

1. Cooley AD, Mullins CE, Gooch JB. Aneurysm of right-sided cervical arch: surgical removal and graft replacement. J Thorac Cardiovasc Surg. 1976;72:106-8.

2. Caus T, Gaubert JY, Monties JR, Moulin G, Mouly A, Cornen A, et al. Right-sided aortic arch: surgical treatment of aneurysm arising from a Kommerell's diverticulum and extending to the descending thoracic aorta with an aberrant left subclavian artery. Cardiovasc Surg. 1994;2: 110-3.

3. Robinson BLAC, Nadolny EM, Entrup MH, Svensson LG. Management of right-sided aortic arch aneurysms. Ann Thorac Surg. 2001;72: 1764-5.

4. Tsukube T, Ataka K, Sakata M, Wakita N, Okita Y. Surgical treatment of an aneurysm in the right aortic arch with aberrant left subclavian artery. Ann Thorac Surg. 2001;71:1710-1. 